\title{
Predictors of Hands-On Learning: Students' Problem Approach Attitude, Problem Solving Confidence, and Problem Solving Style Relevant to Parental Monitoring
}

\author{
Chi-Ruei Tsai \\ Department of Industrial Education, National Taiwan Normal University, 162, Heping East Road Section 1, \\ Taipei, Taiwan \\ Email: bass2143@gmail.com
}

Received January 2014

\begin{abstract}
Helicopter parents prevail in this current society, their monitoring practice was assumed to take their children away from many hands-on engagements and affect children's problem solving skills. Accordingly, this study conducted a questionnaire survey to those vocational high school students who had ever experienced project making, and there were 456 effective questionnaires collected for confirmatory factor analysis and structural equation modeling. The results showed that: 1) parental monitoring was negatively correlated to problem solving confidence, problem solving style, and problem approaching attitude. 2) Students' problem solving confidence, problem solving style, and problem approach attitude were positively associated with hands-on learning attitude. The results implied that parents ought to give children more opportunities to behave themselves, so children would have higher foci of hands-on practice which special needed in vocational high school.
\end{abstract}

\section{Keywords}

Parental Monitoring, Hands-On Learning Attitude, Problem Solving Confidence, Problem Solving Style, Problem Approach Attitude

\section{Introduction}

The level of parental monitoring is used to interpret the mentally interact between parents and their children [1]. There are plenty of studies on how the parents access the children's information, the readiness of their interaction, etc. In these days, present studies of parental monitoring are focusing on the influences of parental monitoring and schooling [2], self-control of children [3], and academic achievement [4]. The former studies show that parental monitoring effects on the teen's problem solving skills [5]. However, there is no study focuses on the relationship of parental monitoring, hands-on learning attitude, problem approach attitude, problem solving 
confidence, and problem solving style. Hands-on learning is regarded as an efficient way of learning science and math, due to the implement of experiential education [6]. The present empirical researches show that there are significant correlations between hands-on learning attitude, problem approach attitude, problem solving confidence, and problem solving style [7] [8].

This study conducted a questionnaire survey to those vocational high school students who had ever experienced project making, to understand the relationship between hands-on learning attitude, problem approach attitude, problem solving confidence, problem solving style, and parental monitoring.

\section{Theoretical Background}

\subsection{Parental Monitoring, Problem Approach Attitude, Problem Solving Confidence, and Problem Solving Style}

The results of "An investigation of interpersonal problem solving approaches with respect to attachment styles" support that the attachment styles was negative correlation with their problem solving skills [9]. The result of further studies supported that parents do effect their children's problem solving skills [10] and academic selfefficacy [11]. The three hypotheses were proposed to guide this study as follows.

H1-1: Parental monitoring is positively correlated with problem approach attitude.

H1-2: Parental monitoring is positively correlated with problem solving confidence.

H1-3: Parental monitoring is positively correlated with problem solving style.

\subsection{Problem Approach Attitude, Problem Solving Confidence, Problem Solving Style, and Hands-On Learning Attitude}

Problem solving skills include how the individual awareness, evaluates, plans, and makes a decision, and the problem approach attitude, problem solving confidence, and problem solving style is correlated to learning attitude [8]. Thus, another three hypotheses guided this study were proposed as follows.

H2-1: Problem approach attitude is positively correlated with hands-on learning attitude.

H2-2: Problem solving confidence is positively correlated with hands-on learning attitude.

H2-3: Problem solving style is positively correlated with hands-on learning attitude.

\section{Research Design}

\subsection{Research Model}

The main purpose of this study is to explore the relationship of hands-on learning attitude, problem approach attitude, problem solving confidence, problem solving style, and parental monitoring. According to the former research mentions above, the research model is shown in Figure 1.

\subsection{Research Procedure}

To achieve the purpose of this study, a questionnaire survey to those purposive sampled vocational high school students who had ever experienced project making were conducted. The questionnaires were collected anonymously by teachers, and the teachers would ensure that the participants were fully understood the procedures and the purposes of this research.

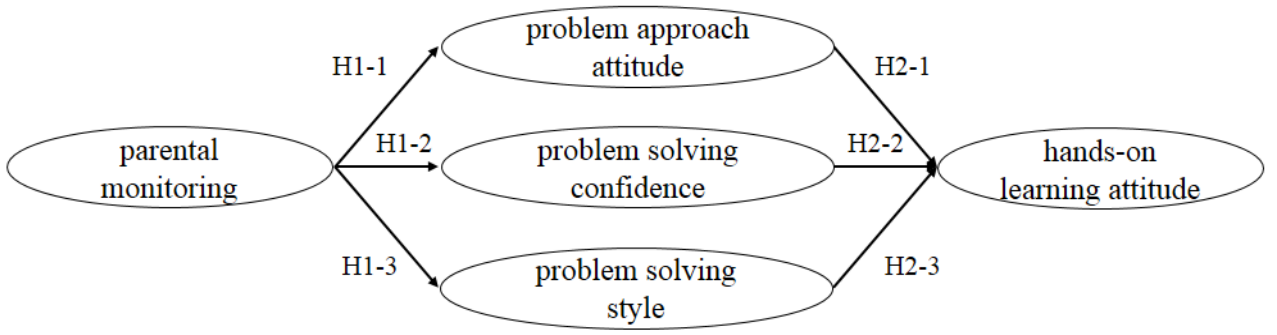

Figure 1. Research hypotheses. 


\subsection{Data Collection and Participants}

The purposive sampling was adopted in this study. To achieve the purposes, $10^{\text {th }}$ grade to $12^{\text {th }}$ grade vocational school students were chosen as study subjects. A total of 493 questionnaires were returned, 456 of which replied all items completely. Of the respondents, $44.5 \%$ were female and $55.5 \%$ were male. All of the participants had the experience of project making curriculum, $24.6 \%$ were 10 th grade, $41.2 \%$ were 11 th grade, and while $34.2 \%$ were $12^{\text {th }}$ grade.

\section{Research Instruments}

\subsection{Research Tool}

The study constructs were measured using multiple items, and they all designed fully anchored, five-point, Likert-type scales that ranged from "strongly disagree" to "strongly agree". The measuring items of parental monitoring were adapted from previously validated research by "parent involvement inventory" (Illinois State Board of Education, 1994) [12], students' problem approach attitude were adapted from previously validated research by Heppner (1995) [13], problem solving confidence were adapted from previously validated research by Zhang \& Schwarzer (1995) [14], problem solving style were adapted from previously validated research by Sternberg (1997) [15], and hands-on learning attitude were adapted from previously validated research by Wittman (2010) [6].

\subsection{Reliability and Validity Analyses}

The total samples of this study were 456 . The whole fit of the structural equation modeling was assessed by $\chi^{2}=$ 612.63 , and the degree of freedom is 164 . To evaluate the consistency of the variables, a reliability analysis of the questionnaire was conducted using Cronbach's $\alpha$. The reliability coefficient for the entire questionnaire was 0.849, while 0.725 were parental monitoring, 0.833 were problem solving confidence, 0.686 were problem solving style, 0.879 were problem approach attitude, hands-on learning attitude were 0.821 . According to the Cronbach's $\alpha$ values above, that indicates that a measure of internal reliability is acceptable.

\section{Research Results}

\subsection{Correlation Analyses}

The result of Pearson product-moment correlation coefficients are presented in Table 1. It shows that there were significant positive correlations among hands-on learning, problem approach attitude, problem solving confidence, problem solving style, and parental monitoring and that there was a certain degree of correlation among these continuous variables.

After testing the reliability and validity of the model, this study estimated the prediction and explanatory abilities of the structural equation model. The result shows that hypotheses H1-1, H1-2, H1-3, H2-1, H2-2, and H2-3 were supported. These results indicated that the parental monitoring had a direct significant positive correlation with hands-on learning students' problem approach attitude, problem solving confidence, and problem solving style. Furthermore, hands-on learning, students' problem approach attitude, problem solving confidence, and problem solving style had direct significant positive correlations with each other.

Table 1. The correlation matrix.

\begin{tabular}{|c|c|c|c|c|c|}
\hline & $\begin{array}{c}\text { Parental } \\
\text { monitoring }\end{array}$ & $\begin{array}{c}\text { Parental } \\
\text { monitoring }\end{array}$ & $\begin{array}{c}\text { Parental } \\
\text { monitoring }\end{array}$ & $\begin{array}{c}\text { Parental } \\
\text { monitoring }\end{array}$ & $\begin{array}{c}\text { Parental } \\
\text { monitoring }\end{array}$ \\
\hline Parental monitoring & 1 & & & & \\
\hline Problem approach attitude & $0.151^{* *}$ & 1 & & & \\
\hline Problem solving confidence & $0.161^{* *}$ & $0.529^{* *}$ & 1 & & \\
\hline Problem solving style & $0.198^{* *}$ & $0.442^{* *}$ & $0.344^{* *}$ & 1 & \\
\hline Hands-on learning attitude & $0.143^{* *}$ & $0.255^{* *}$ & $0.329^{* *}$ & $0.243^{* *}$ & 1 \\
\hline
\end{tabular}

$p<0.001^{* * *}, p<0.01^{* *}, p<0.05^{*}$. 


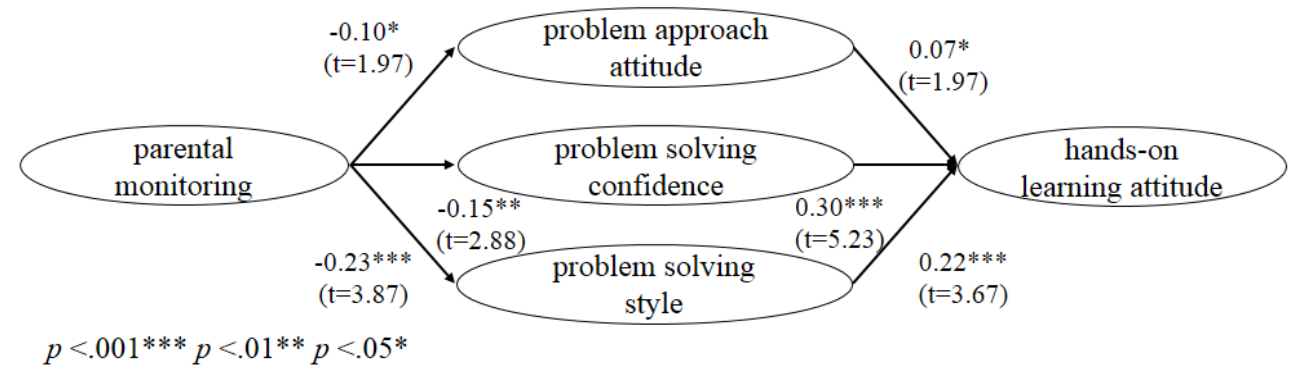

Figure 2. Path coefficient analysis.

\subsection{Structural Model Testing}

A structural equation modeling (SEM) was conducted to test the hypotheses of this study. The whole fit of the structural equation modeling was assessed by $\chi^{2}=612.63$. Since $\chi^{2}$ is inclined to be affected by sample size, therefore, other fit indices were calculates in this research. The values of RMSEA were 0.078 , which indicates that the measurement model was a reasonable model fit. Others indices were greater than or near 0.9, which indicates that the structural model is acceptable $(\mathrm{NFI}=0.92$; NNFI $=0.93$; CFI $=0.94$; IFI $=0.94$; $\mathrm{RFI}=0.91$; $\mathrm{GFI}=0.88$; AGFI $=0.85$ ). In summary, the results indicate that the researching model is adequate.

\subsection{Path Coefficient Analysis}

Since the result of reliability analyses, validity analyses, and structural model testing shows that the researching model is adequate. The results of path analysis were listed as follow. Figure 2 shows the parental monitoring had a direct significant positive correlation with students' problem approach attitude ( $\mathrm{t}=1.97, \beta=-0.10)$, problem solving confidence $(\mathrm{t}=2.88, \beta=-0.15)$, and problem solving style $(\mathrm{t}=3.87, \beta=-0.23)$. Furthermore, students' problem approach attitude, problem solving confidence, and problem solving style had a direct significant positive correlation with hands-on learning attitude $(\mathrm{t}=1.97, \beta=0.07 ; \mathrm{t}=5.23, \beta=0.30 ; \mathrm{t}=3.67, \beta=0.22)$.

\section{Findings}

The hypotheses of the study tend to explain the relations of hands-on learning attitude, students' problem approach attitude, problem solving confidence, problem solving style, and parental monitoring. The main findings of the study are as followed. The results of this study support the hypotheses, that is parental monitoring was negatively correlated to problem solving confidence, problem solving style, and problem approaching attitude. Besides, other results indicate that students' problem solving confidence, problem solving style, and problem approach attitude were positively associated with hands-on learning attitude.

\section{References}

[1] Hayes, L., Hudson, A. and Matthews, J. (2007) Understanding Parental Monitoring through Analysis of Monitoring Episodes in Context. International Journal of Behavioral Consultation and Therapy, 3, 96-108.

[2] Kilian, B., Hofer, M. and Kuhnle, C. (2013) Conflicts between On-Task and Off-Task Behaviors in the Classroom: The Influences of Parental Monitoring, Peer Value Orientations, Students' Goals, and Their Value Orientations. Social Psychology of Education, 16, 77-94. http://dx.doi.org/10.1007/s11218-012-9198-y

[3] Ozdemir, Y., Vazsonyi, A.T. and Cok, F. (2013) Parenting Processes and Aggression: The Role of Self-Control among Turkish Adolescents. Journal of Adolescence, 36, 65-77. http://dx.doi.org/10.1016/j.adolescence.2012.09.004

[4] Glaesser, J. and Cooper, B. (2012) Gender, Parental Education, and Ability: Their Interacting Roles in Predicting GCSE Success. Cambridge. Journal of Education, 42, 463-480. http://dx.doi.org/10.1080/0305764X.2012.733346

[5] Miller, S.R., Brody, G.H. and Murry, V.M. (2010) Mothers’ and Fathers’ Responsive Problem Solving with Early Adolescents: Do Gender, Shyness, and Social Acceptance Make a Difference? Journal of Child and Family Studies, 19, 298-307. http://dx.doi.org/10.1007/s10826-009-9297-3

[6] Wittman, W. (2010) Hands-On Practice Helps Students Master IT Skills and Succeed. Educause Quarterly, 33.

[7] Hong, J.C., Chen, M.Y., Wong, A., Hsu, T.F. and Peng, C.C. (2012) Developing Physics Concepts through Hands-On 
Problem Solving: A Perspective on a Technological Project Design. International Journal of Technology and Design Education, 22, 473-487. http://dx.doi.org/10.1007/s10798-011-9163-7

[8] Eskin, M. (2013) Problem Solving Therapy in the Clinical Practice. Elsevier Insights, New York.

[9] Arslan, E., Arslan, C. and Ari, R. (2012) An Investigation of Interpersonal Problem Solving Approaches with Respect to Attachment Styles. Educational Sciences: Theory and Practice, 12, 15-23.

[10] Shokoohi-Yekta, M., Parand, A., Zamani, N., Lotfi, S. and Ayazi, M. (2011) Teaching Problem-Solving for Parents: Effects on Children's Misbehavior. Procedia-Social and Behavioral Sciences, 30, 163-166. http://dx.doi.org/10.1016/j.sbspro.2011.10.032

[11] Fan, W. and Williams, C.M. (2009) The Effects of Parental Involvement on Students' Academic Self-Efficacy, Engagement and Intrinsic Motivation. Educational Psychology, 30, 53-74. http://dx.doi.org/10.1080/01443410903353302

[12] Illinois State Board of Education (1994) Parent Involvement Inventory. http://www.ncrel.org/sdrs/areas/issues/envrnmnt/famncomm/pa4lk12.htm

[13] Heppner, P.P. and Petersen, C.H. (1982) The Development and Implications of a Personal Problem-Solving Inventory. Journal of Counseling Psychology, 29, 66. http://dx.doi.org/10.1037/0022-0167.29.1.66

[14] Zhang, J.X. and Schwarzer, R. (1995) Measuring Optimistic Self-Beliefs: A Chinese Adaptation of the General SelfEfficacy Scale. Psychologia, 38, 174-181.

[15] Sternberg, R.J. (1997) Thinking Styles. Cambridge University Press. http://dx.doi.org/10.1017/CBO9780511584152 